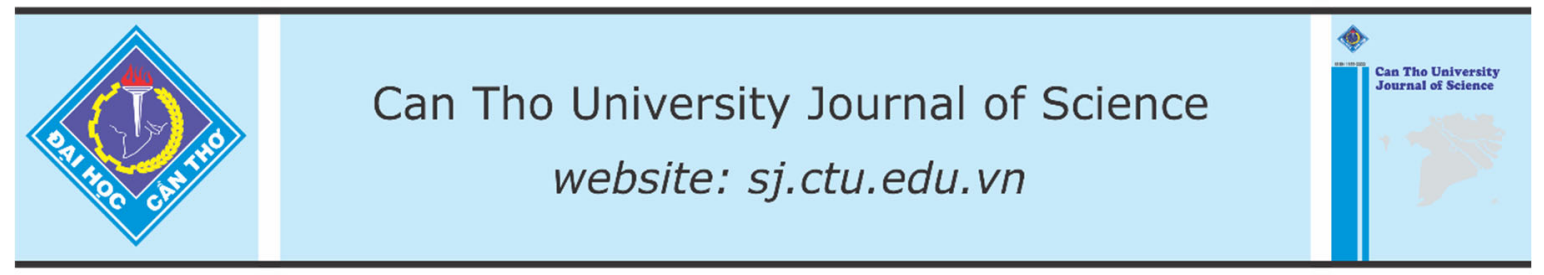

DOI: 10.22144/ctu.jen.2019.001

\title{
Antifeedant activity of essential oil Lantana camara L. against Spodoptera litura Fabr. (Lepidoptera: Noctuidae) and Plutella xylostella Curtis (Lepidoptera: Plutellidae)
}

\author{
Nguyen Ngoc Bao Chau ${ }^{1 *}$, Dong Thi Cam Tu${ }^{1}$ and Nguyen Bao Quoc ${ }^{2}$ \\ ${ }^{I}$ Department of Agricultural Biotechnology, Faculty of Biotechnology, Ho Chi Minh City Open University, \\ Vietnam \\ ${ }^{2}$ Research Institute for Biotechnology and Environment, Nong Lam University, Vietnam \\ ${ }^{*}$ Correspondence: Nguyen Ngoc Bao Chau (email: chau.nnb@ou.edu.vn)
}

\section{Article info.}

Received 05 Oct 2018

Revised 29 Dec 2018

Accepted 29 Mar 2019

\section{Keywords}

Antifeedant, essential oil, Lantana camara, Plutella xylostella, Spodoptera litura

\begin{abstract}
The main volatile components of leaf extracts from Lantana camara by gas chromatography-mass spectrometry (GC-MS) were identified as $\beta$-caryophyllene $(29.67 \%)$, caryophyllene oxide $(2.69 \%), \alpha$-humulene $(10.24 \%)$ and germacrene D $(1.72 \%)$. The antifeedant activity of Lantana camara essential oil was tested against Spodoptera litura and Plutella xylostella at different concentrations. Results indicated that $50 \%-60 \%$ antifeedant activity induced by the oil was recorded on Spodoptera litura and Plutella xylostella second instar larvae and gave significant difference compared to the control $(P=0.0000)$ in no-choice test and choice-test experiments, respectively; the essential oil of Lantana camara affected the ratio of pupation and adult emergence of both $S$. litura and P. xylostella.
\end{abstract}

Cited as: Chau, N.N.B., Tu, D.T.C. and Quoc, N.B., 2019. Antifeedant activity of essential oil Lantana camara L. against Spodoptera litura Fabr. (Lepidoptera: Noctuidae) and Plutella xylostella Curtis (Lepidoptera: Plutellidae). Can Tho University Journal of Science. 11(1): 1-6.

\section{INTRODUCTION}

In Vietnam, developing biopesticides from natural plant-derived products plays an important role through promoting sustainable agriculture. Therefore, increasing the efficiency of Integrated Pest Management (IPM) program, particularly using biopesticides to manage Lepidopteran pests is paid attention nationally and worldwide. Moreover, Spodoptera litura and Plutella xylostella are the most devastating insect pests of brassicaceous crops and have developed resistance to many chemical pesticides.

Many different plant species have useful compounds that can be used as biopesticides. Scientists have reported that the leaf extracts from Elsholtzia cristata have antifeedant activity to Pieris rapae (Nguyen Ngoc Hoa et al. 2012). Lantana camara distributes to subtropical and tropical regions of the world which contains phenolics, flavonoids, alkaloids, triterpenes, saponin, terpenoids, etc. having the ability to kill mosquito $3^{\text {rd }}$ and $4^{\text {th }}$ instars (Kalita et al. 2012). It was reported that this plant has been used in many places for treating various human illnesses, and the plant extracts have exhibited a broad range of biological activities (Sharma et al. 2007). Besides, Ogendo et al. (2004) reported that the plant has been shown to have toxic and repellent effects against stored grains pests. Essential oils and their constituents from leaves and flowers of L. camara showed fumigants against stored product insects (Zoubiri and Baaliouamer, 2012). Some scientists have reported the insecticidal activities of $L$. camara essential oil on Sitophilus spp. (Mohamed and Abdelgaleil, 2008; Zoubiri and Baaliouamer, 2011) and 
Tribolium castaneum (Coleoptera: Tenebrionidae) (Mohamed and Abdelgaleil, 2008). The objective of the study was to determine the basic volatile components of essential oil from leaves and fumigant toxicity of essential oil of L.camara growing in Binh Duong province against $S$. litura and $P$. xylostella.

\section{MATERIALS AND METHODS}

\subsection{Plant materials and essential oils}

The fresh leaves of $L$. camara were collected in Binh Duong province from their natural habitats. Collected leaves were washed and kept in plastic bags inside a refrigerator until the time for oil extraction. The essential oils were obtained by hydrodistillation method using a Clevenger type apparatus.

\subsection{Insect culture}

Plutella xylostella larvae were collected at Brassica integrifolia vegetable fields in Hoc Mon and Spodoptera litura at swamp morning-glory (Ipomoea aquatica) in $\mathrm{Cu} \mathrm{Chi}$, Ho Chi Minh City and were reared until the second generation on leaves of Brassica integrifolia at room temperature $\left(28 \pm 2^{\circ} \mathrm{C}\right)$ with 16-8 L:D condition. Second instar larvae of $P$. xylostella and $S$. litura were used for experiments.

\subsection{Gas chromatography}

The analyses of the essential oil compounds were sent to Vietnam National University Ho Chi Minh City, University of Science, 227 Nguyen Van $\mathrm{Cu}$ Street, Ward 4, District 5, Ho Chi Minh City, Viet Nam for GC-MS system analysis.

\subsection{Antifeedant activity of essential oils}

The experiments were conducted with 5 treatments of essential oil 1, 5, 10, 100 and $500 \mu \mathrm{L}$, and $50 \mu \mathrm{L}$ acetone was used as control treatment.

No-choice test method was conducted to study the antifeedant activity of crude extracts. Fresh $B$. integrifolia and swamp morning-glory leaf discs of $1 \mathrm{~cm}$ diameter were punched using the cork borer and then treated each with $1,5,10,100$ and $500 \mu \mathrm{L}$ of essential oil in $50 \mu \mathrm{L}$ acetone treatments. Larvae were starved 3-4 hours prior to experimentation, then second instar larvae were introduced to plastic petri dish $(1.5 \mathrm{~cm} \times 9 \mathrm{~cm})$ containing wet filter paper to avoid early drying of the leaf discs. No-choice test method was calculated using the leaf disc method (Zandi-Sohani et al. 2012):

Antifeedant index $(\%)=[1-(\mathrm{C}-\mathrm{T}) /(\mathrm{C})] \mathrm{x} 100]$ where " $\mathrm{C}$ " is the weight of leaf disc and " $\mathrm{T}$ " is the weight of leaf discs remained in the treatment after 24 hours.

Choice test method was conducted by the method as previously described. Half of filter paper (5 leaves, $1 \mathrm{~cm}^{2} /$ each leaf) was impregnated with $50 \mu \mathrm{L}$ acetone and another half were treated with acetone solutions of different concentrations of essential oil treatment $(1,5,10,100$ and, $500 \mu \mathrm{L}$, respectively) and dried for 10 minutes at room temperature. Three replicates were maintained for each treatment. Five larvae of S. litura and 10 larvae of $P$. xylostella per replicate were exposed separately. The antifeedant activity was calculated using the formula of Caasi (1983):

Antifeedant index $(\%)=[(\mathrm{Co}-\mathrm{Ci}) /(\mathrm{Co})] \times 100$

where "Co" is the weight of leaf disc consumed in the control and " $\mathrm{Ci}$ " is the weight of leaf discs consumed in the treatment.

\subsection{Statistical analysis}

The antifeedant, larvicidal and pupicidal activities were subjected to analysis of variance (ANOVA) followed by Duncan, Statgraphics plus 3.0 software.

\section{RESULTS AND DISCUSSION}

\subsection{Chemical composition of essential oil}

Table 1: Volatile composition of the essential oil from Lantana camara leaves

\begin{tabular}{lrrr}
\hline \multirow{2}{*}{ Volatile compounds } & \multicolumn{3}{c}{$\begin{array}{r}\text { Concentration (\% peak } \\
\text { area) }\end{array}$} \\
\cline { 2 - 4 } & In this study & Ref * & Ref ** \\
\hline$\alpha-$-Pinene & 0.79 & 0.25 & - \\
Sabinene & 6.90 & 1.56 & - \\
$\beta-$-Pinene & 1.01 & - & - \\
$\beta-$ Myrcene & 0.48 & 0.67 & - \\
$\delta$-3-Carene & 1.24 & 0.04 & - \\
1,8-Cinevole & 8.71 & - & - \\
$\beta-$ Elemene & 0.84 & 6.41 & 2.40 \\
$\beta$-Caryophyllene & 29.67 & 35.70 & - \\
$\alpha-$-Humulene & 10.24 & 3.72 & 3.46 \\
Germacrene D & 1.72 & 2.85 & 4.11 \\
Germacrene B & 6.95 & - & 3.18 \\
$\delta$-Cadinene & 1.07 & - & 2.40 \\
Danavone & 2.90 & 0.30 & - \\
Spathulenol & 1.88 & - & 4.08 \\
Caryophyllene oxide & 2.69 & 10.04 & 1.13 \\
\hline
\end{tabular}

(*) Zoubiri and Baaliouamer (2012); (**) Murugesan et al. (2012)

The main volatile composition of $L$. camara by GCMS in this study was identified as: $\beta$-caryophylene $(29.67 \%)$, caryophylene oxide $(2.69 \%), \alpha-$ humulene $(10.24 \%)$ and germacrene D (1.72\%) 
which were also reported responsible for the insecticidal activity (Zoubiri and Baaliouamer, 2012; Zandi-Sohani et al., 2012) (Table 1). ZandiSohani et al. (2012) indicated that genetic, climatic, geographical and seasonal variations caused the difference in quality and quantity of essential oil composition.

\subsection{Antifeedant activity}

Results of the study indicated that the essential oil of $L$. camara gave toxic and repellent effects against both S. litura and $P$. xylostella. It produced high mortality to the $2^{\text {nd }}$ instar larvae of both $P$. xylostella and $S$. litura. Antifeedant activity was found to increase with the essential oil concentration in no choice test experiment. The essential oil at $500 \mu \mathrm{l}$ concentration showed significant difference to other treatments $(\mathrm{P}<0.05)$ and caused almost 50\% antifeedant activity on the exposed larvae (Table 2).

Pupicidal activity of T3-10 treatment was recorded as of $0 \%$ for S. litura and of T4-100 treatment for P. xylostella, respectively. Adult activity was increased corresponding with the increased concentrations of essential oil and showed significant difference to other treatments $(\mathrm{P}<0.05)$ (Table 3).

Table 2: Antifeedant activity of essential oil from Lantana camara on $S$. litura and $P$. xylostella (no-choice test)

\begin{tabular}{lrr}
\hline Name of the & \multicolumn{2}{c}{ Antifeedant index (\%) } \\
\cline { 2 - 3 } treatments & S. litura & $\boldsymbol{P . x y l o s t e l l a}$ \\
\hline T1-1 & $29.63^{\mathrm{e}}$ & $31.17^{\mathrm{d}}$ \\
$\mathrm{T} 2-5$ & $35.39^{\mathrm{d}}$ & $38.98^{\mathrm{c}}$ \\
$\mathrm{T} 3-10$ & $42.15^{\mathrm{c}}$ & $48.06^{\mathrm{b}}$ \\
T4-100 & $50.67^{\mathrm{b}}$ & $51.28^{\mathrm{b}}$ \\
T5-500 & $57.07^{\mathrm{a}}$ & $62.42^{\mathrm{a}}$ \\
T6-acetone & $27.38^{\mathrm{e}}$ & $25.18^{\mathrm{e}}$ \\
cv \% & 4.38 & 5.75 \\
\hline
\end{tabular}

Means within column followed by the same letter were not significantly different by Ducan test. Data were transferred to arcsine prior ANOVA (95\%) and comparison of means.

T1-1: $(1 \mu L$ essential oil $+50 \mu L$ acetone $) ; T 2-5:(5 \mu L$ essential oil $+50 \mu$ L acetone); T3-10: $(10 \mu$ L essential oil $+50 \mu$ L acetone); T4-100: (100 $\mu$ L essential oil +50 $\mu L$ acetone); T5-500: (500 $\mu \mathrm{L}$ essential oil $+50 \mu \mathrm{L}$ acetone); T6-acetone: $50 \mu \mathrm{L}$ acetone.
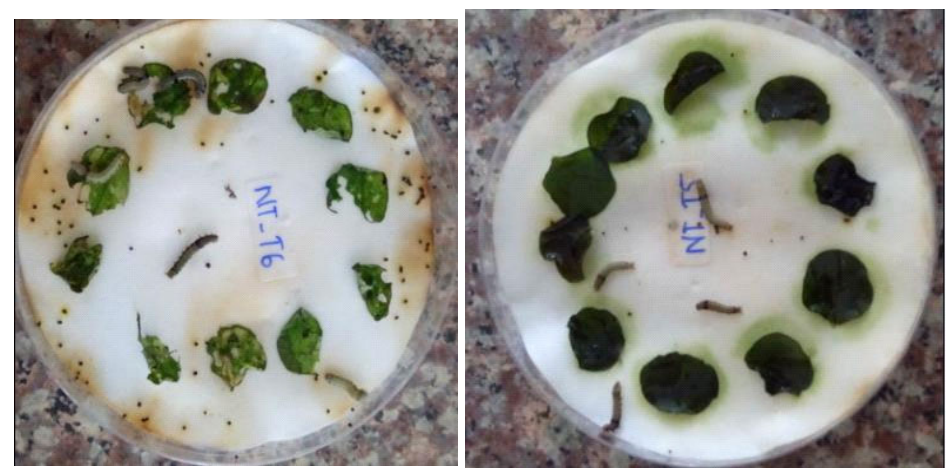

Fig. 1: Antifeedant activity of essential oil from Lantana camara on S. litura (no-choice test)

Left: Control; Right: T5-500 treatment
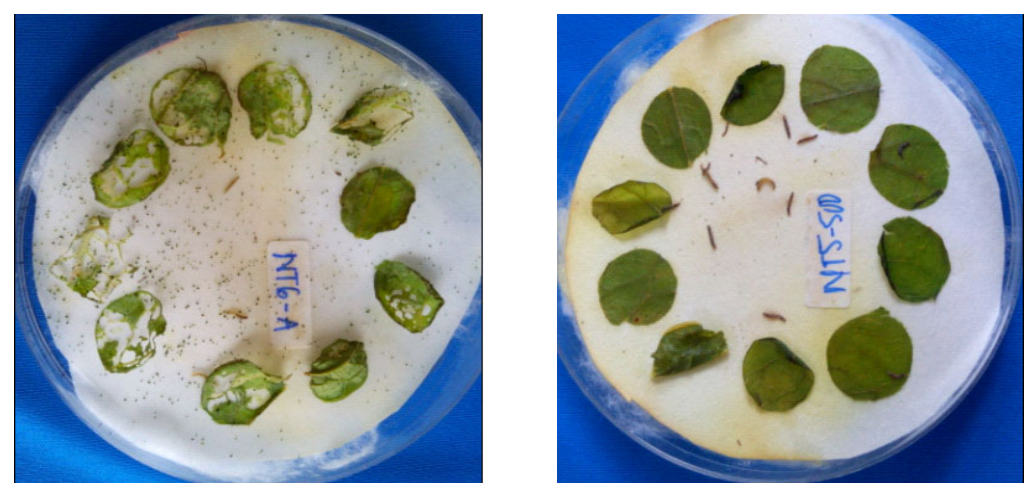

Fig. 2: Antifeedant activity of essential oil from Lantana camara on P. xylostella (no-choice test)

Left: Control; Right: T5-500 treatment 
Table 3: Percentage of pupicial activities and adult activity observed after treatment of essential oil from Lantana camara on $S$. litura and P. xylostella (no - choice test)

\begin{tabular}{lrrrr}
\hline \multirow{2}{*}{$\begin{array}{l}\text { Name of the } \\
\text { treatments }\end{array}$} & \multicolumn{2}{c}{ Spodoptera litura } & \multicolumn{2}{c}{ Plutella xylostella } \\
\cline { 2 - 5 } & $\begin{array}{r}\text { Pupicidal activ- } \\
\text { ity (\%) }\end{array}$ & Adult activity (\%) & Pupicidal activity (\%) & Adult activity (\%) \\
\hline T1-1 & $39.23 \mathrm{c}$ & $30.78 \mathrm{~b}$ & $36.93 \mathrm{c}$ & $26.07 \mathrm{c}$ \\
T2-5 & $30.78 \mathrm{~b}$ & $30.78 \mathrm{~b}$ & $23.85 \mathrm{~b}$ & $21.15 \mathrm{bc}$ \\
T3-10 & $0.00 \mathrm{a}$ & $0.00 \mathrm{a}$ & $21.15 \mathrm{~b}$ & $18.44 \mathrm{~b}$ \\
T4-100 & $0.00 \mathrm{a}$ & $0.00 \mathrm{a}$ & $0.00 \mathrm{a}$ & $0.00 \mathrm{a}$ \\
T5-500 & $0.00 \mathrm{a}$ & $0.00 \mathrm{a}$ & $0.00 \mathrm{a}$ & $0.00 \mathrm{a}$ \\
T6- Acetone & $43.08 \mathrm{c}$ & $43.08 \mathrm{c}$ & $45.00 \mathrm{c}$ & $37.22 \mathrm{~d}$ \\
cv\% & 21.43 & 28.80 & 24.88 & 22.43 \\
\hline
\end{tabular}

Data were transformed into arcsin $\sqrt{ }(x)$ and were analyzed using one-way analysis of variance (ANOVA) followed by Duncan. Means within column followed by the different letters indicate statistically significant differences among groups $(P<0.05)$

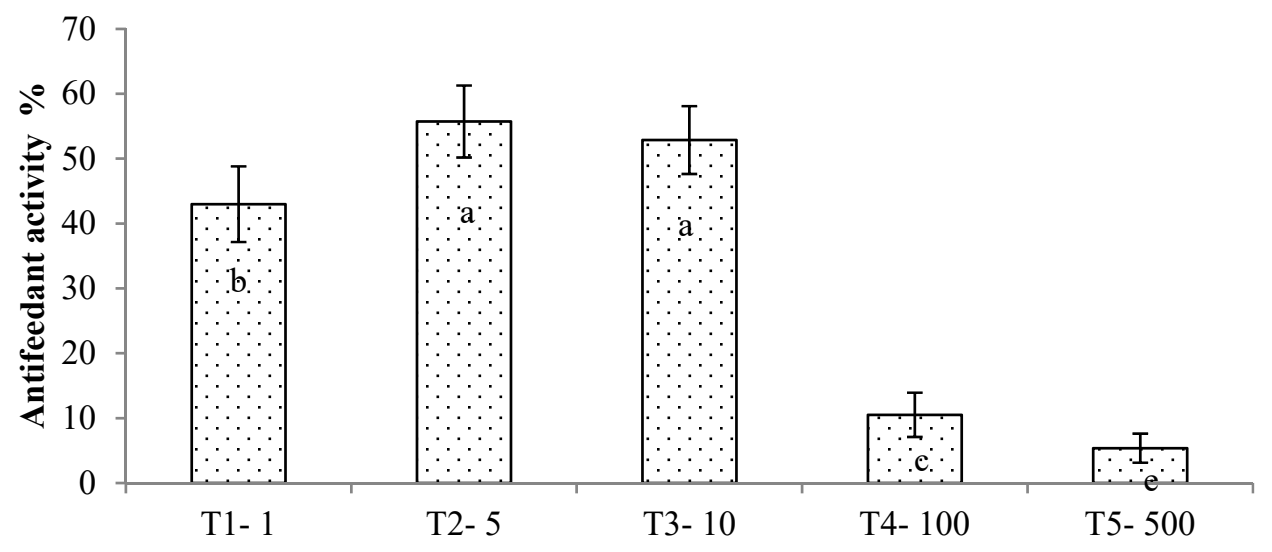

Treatments

Fig. 3: Antifeedant activity of essential oil to $S$. litura (choice test)

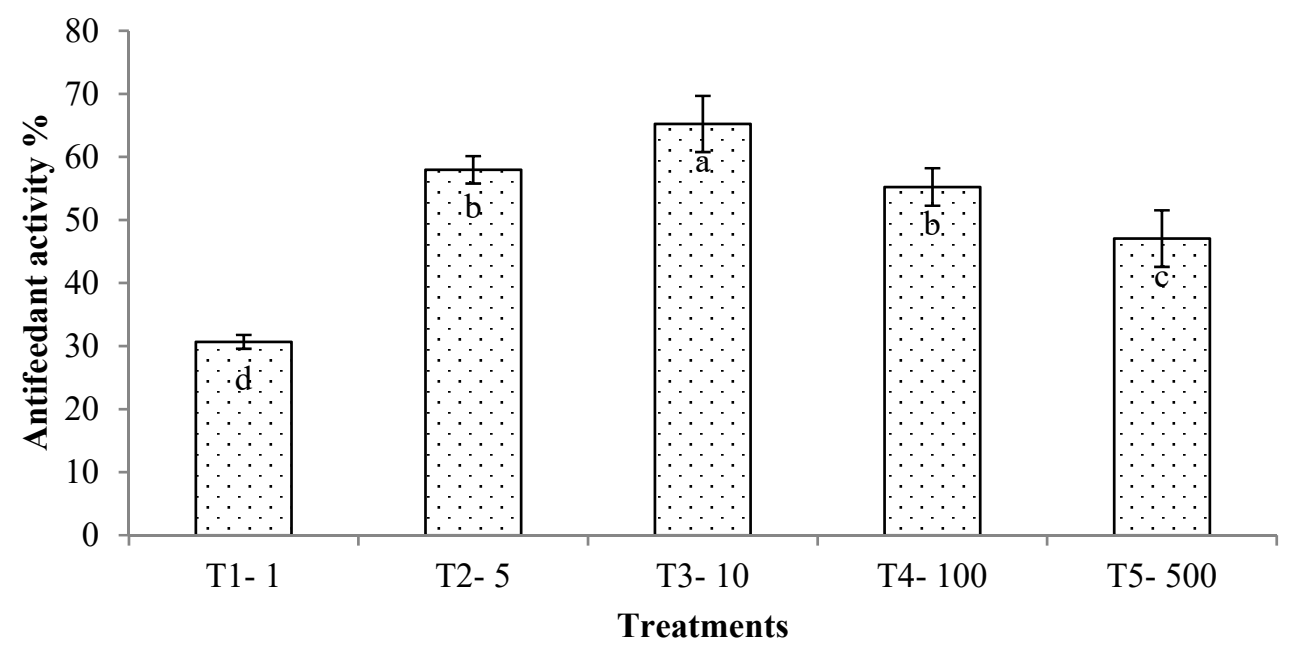

Fig. 4: Antifeedant activity of essential oil to $P$. xylostella (choice test) 
In choice test experiment (Fig. 3 and Fig. 4), the essential oil of $L$. camara also produced high antifeedant activity to the $2^{\text {nd }}$ instar larvae of $S$. litura and $P$. xylostella from T2-5 and T3-10 treatments. However, antifeedant activity was found to decrease as the essential oil concentration increased. This result can be explained as the concentration of essential oil of L. camara was high at T4-100 and T5-500 treatments and active compounds effected to the control leaves when leaves were put together in choice test experiment.

Lantana camara is toxic and feeding deterrent to both S. litura and P. xylostella. The presence of $\beta$ caryophyllene, caryophyllene oxide, germacrene $\mathrm{B} / \mathrm{D}$ were analyzed in this study (Table1) indicated the effectiveness of essential oil of L. camara, as the same result was also obtained by Zoubiri and Baaliouamer (2012). Studies have been reported the deterrent activity of plant extracts and the essential oil of L. camara against Reticulitermes flavipes (Yuan and $\mathrm{Hu}, 2012$ ) and Sitophilus granarius adults (Zoubiri and Baaliouamer, 2012), respectively. The ability of antibacterial, antimicrobial and antifungal activities of essential oil of $L$. camara have been intensively studied by Siddiqui et al. (1995). The plant also has been shown to have toxic and repellent affects against insect pests of stored grains (Ogendo et al., 2004) and adult termite workers (Verma and Verma, 2006).

Many plant secondary metabolites are known as antifeedant and toxic to insect larvae such as triterpenes, sequiterpene lactones and alkaloids (Paul and Saha, 2012). Baskar et al. $(2009,2010)$ reported that the antifeedant activity was due to the presence of alkaloids, some plant extracts against P. xylostella such as Acorus calamus L. (Areceae), Azadirachta indica A. Juss, Melia azedarach L. (Meliaceae), and Acalypha fruticosa F. (Euphorbiaceae) (Lingathurai et al., 2011). There are seventy-four triterpenoids have been isolated from different Lantana species, especially lantadenes are considered as the main bioactive constituents (Sharma et al., 2007). However, scientists have not conducted experiments to understand the insecticidal mechanisms of the actions of these chemical constituents.

\section{CONCLUSIONS}

In this study, significant insecticidal and antifeedant activities against $S$. litura and $P$. xylostella were first observed in essential oil of $L$. camara suggesting a future exploitation for the isolation of active molecules and to develop a new botanical formulation for sustainable agriculture in Vietnam. The results described the role of biopesticide of essential oil of $L$. camara on insect pests. More experiments on other lepidopteran pests are needed to conduct in the future.

\section{ACKNOWLEDGEMENTS}

Our sincere thanks are sent to Ho Chi Minh City Open University, Vietnam for financial support (Grant number D2014).

\section{REFERENCES}

Baskar, K., S. Kingsley, S.E. Vendan, M.G. Paulraj, V. Duraipandiyan and S. Ignacimuthu, 2009. Antifeedant larvicidal and pupicidal activities of Atalantia monphylla (L.) Correa against Helicoverpa armigera (Hubner) (Lepidoptera: Noctuidae). Chemosphere, 75(3): 355-359.

Baskar, K., R. Maheshwaran and K.S. Ignacimuthu, 2010. Bioefficacy of Couroupita guianensis (Aubl) against Helicoverpa armigera (Hub.) (Lepidoptera: Noctuidae) larvae. Spanish Journal of Agricultural Research, (1): 135-141.

Caasi, M.T., 1983. Morphogenetic effects and antifeedant properties of Aristolochia tagala Cham. and A. elegans Motch on several lepidopterous insects, Bachelor thesis. University of the Philippines, Los Banos, College, Laguna.

Kalita, S., Kumar G., Karthik L. and Rao K.V.B., 2012. A Review on Medicinal Properties of Lantana camara Linn. Research Journal of Pharmacy and Technology, 5(6): 711.

Li, P., Huo L., Su, W., et al., 2011. Free radical-scavenging capacity, antioxidant activity and phenolic content of Pouzolzia zeylanica. Journal of the Serbian Chemical Society, 76(5): 709-717.

Lingathurai, S., Vendan S. E., Paulraj M. G., and Ignacimuthu S., 2011. Antifeedant and larvicidal activities of Acalypha fruticosa Forssk. (Euphorbiaceae) against Plutella xylostella L. (Lepidoptera: Yponomeutidae) larvae. Journal of King Saud University-Science, 23(1): 11-16.

Mohamed, M.I.E., and Abdelgaleil, S.A.M., 2008. Chemical composition and insecticidal potential of essential oils from Egyptian plants against Sitophilus oryzae (L.) (Coleoptera: Curculionidae) and Tribolium castaneum (Herbst) (Coleoptera: Tenebrionidae). Appl. Entomol. Zool. 43(4): 599-607.

Murugesan S., Rajeshkannan C., Suresh Babu D., Sumathi R., and Manivachakam P., 2012. Identification of insecticidal properties in commonweed Lantana camara Linn by Gas Chromatography and Mass Spectrum (GC-MS-MS). Advances in Applied Science Research, 3(5): 2754-2759.

Nguyen Ngoc Hoa, Dinh Thi Phuong, Nguyen Van Du et al., 2012. Investigation of killing and antifeedant effects on Pieris rapae larva of extracts from some potential plant species. Journal of scientifc research anh development 9: 535-541 (in Vietnamese).

Ogendo, J.O., Deng A.L., Belmain, S.R., Walker D.J., and Musandu A.A.O., 2004. Effect of insecticidal 
plant materials, Lantana camara L. and Tephrosia vogelii Hook, on the quality parameters of maize stored grains. Journal of food technology in Africa, 9(1): 29-35.

Paul, S. and Saha D., 2012. Pharmacognostic Studies of Aerial Part of Pouzolzia zeylanica (L.), Asian Journal of Pharmacy and Technology, 2(4): 141-142.

Siddiqui, B.S., Raza S.M., Begum S., Siddiqui S., Firdous S., 1995. Pentacyclic triterpenoids from Lantana Camara. Phytochemistry, 38 (1995): 681-685.

Sharma, O. P., Sharma S., Pattabhi V., Mahato S.B., and Sharma P.D., 2007. A review of the hepatotoxic plant Lantana camara. Critical reviews in toxicology, 37(4): 313-352.
Verma, R.K., and Verma, S.K., 2006. Phytochemical and termiticidal study of Lantana camara var. Fitoterpia 77(6):466-468.

Yuan, Z. and Hu, X. P., 2012. Repellen, antifeedant, and toxic activities of Lantana camara leaf extract against Reticulitermes flavipes (Isoptera: Rhinotermitidae) Journal of Economic Entomology, 105(6): 2115-21.

Zandi-Sohani N., Hojjati M., Angel A., and Barrachina C., 2012. Bioactivity of Lantana camara L. essential oil against Callosobruchus maculatus (Fabricius). Chilean Journal of Agricultural Research, 72(4): 502.

Zoubiri, S., and Baaliouamer, A., 2012. GC and GC/MS analyses of the Algerian Lantana camara leaf essential oil: Effect against Sitophilus granarius adults. Journal of Saudi Chemical Society, 16(3): 291-297. 